International Journal of Critical Indigenous Studies

Volume 9, Number 2, 2016

Vision led = vision fed: NIRAKN's role in progressing scholarship in Aboriginal early childhood education, raising the bar in Aboriginal knowledges in higher education and holding ground in Aboriginal research capacity building

Author

Dr Karen L. Martin

\title{
Autobiographical information
}

Dr Karen L. Martin. Noonuccal clan of the Quandamoopah nation (paternal) and Bidjara nation (maternal). Areas of expertise: Aboriginal knowledges and worldview, Indigenous research, early childhood education, Indigenous early childhood education.

\section{Affiliations}

School of Education and Professional Studies, Griffith University; Griffith Institute of Educational Research; the National Indigenous Knowledges and Research Network; and the Indigenous Research Network, Griffith University.

\section{Abstract}

As the National Indigenous Knowledges and Research Network (NIRAKN) reaches its completion as an entity in 2016, this paper takes up the invitation to its members to write about the key learnings, benefits and challenges experienced as a member of NIRAKN's Indigenous Sociology, Indigenous Knowledge and Technology node. The author discusses the role of NIRAKN in progressing the scholarship of Aboriginal early childhood education through its collaborative research program, raising the bar regarding Aboriginal knowledges in higher education through its network connections and aspects for holding ground in Aboriginal research capacity building, particularly in the area of qualitative research methodologies. These discussions serve to highlight that, as the NIRAKN model has been led by a strong vision, it has fed change and achieved its visions.

\section{Keywords}

Indigenous education, Indigenous early childhood education, Indigenous voices, Indigenous research, Aboriginal knowledges.

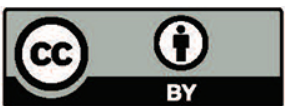




\section{Abbreviations}

AFK

AJEC

AKinHE

CIEC

ECR

LSIC

NIRAKN

OLT

PGS
Aboriginal Knowledges Framework

Australasian Journal of Early Childhood

Aboriginal knowledges in higher education

Contemporary Issues in Early Childhood

early career researchers

Longitudinal Study of Indigenous Children

National Indigenous Knowledges and Research Network

Office of Learning and Teaching

post-graduate students

\section{Introduction}

In 2008, 78 Aboriginal and Torres Strait Islander child participants in the 'Longitudinal Study of Indigenous Children - Footprints in Time' were asked what they wanted to be or do when they got older. The two highest responses were 'police' $(n=72)$ and 'teachers' $(n=71)$.

Given the nature of relationships between Indigenous Australians and the police, the Australian legal system and its institutions, the fact that these young Indigenous Australian children stated policing as a career goal is puzzling. Likewise, that they identified teaching as a career is curious, given that school attendance statistics, since the 1960s, have persistently portrayed that there are issues with the relationships between schools and teachers, and many young Indigenous Australians. However, schooling is not the focus of this paper. Its focus is the two ends of the education continuum, namely early childhood education and higher education. Principles of critical race theory, especially the use of stories for "understanding education inequity" (Ladson-Billings 1998, 7). Stories are core to Indigenous Australian epistemology. The stories come from the knowledge and experiences of the author, who is a Noonuccal, Quandamoopah woman with some 15 years' experience in early childhood education and with some 20 years' experience as an academic and who researches the disciplines of education and Indigenous Australian Studies in higher education. In the latter, she was also a member of the National Indigenous Knowledges and Research Network (NIRAKN) and the Indigenous Knowledge and Indigenous Sociology and Technology node. Thus, these stories are epistemic devices that "give voice" (Ladson-Billings 1998, 2009; Lazos Vargas 2003) to elucidate the nature of the inequities that occur in these two sectors of education for Indigenous Australians. The stories are provided as a means to interrogate the roles of Indigenous Australian women in early childhood education and the role of Indigenous knowledges in higher education. The stories, as epistemic devices, also enable the role of the NIRKAN to be explored in relation to advancing the scholarship in Indigenous Australian early childhood education, raising the bar within Indigenous Australian higher education, and areas that are merely 'holding ground' regarding capacity building for Indigenous Australian researchers.

\section{'Are there any women here?' Yes, they're white and middle-class: A brief story about early childhood education and some Australian features}

The education of very young children, aged from birth to four or five years is a post-World War II phenomenon. Prior to this, programs for children were the province of philanthropic or religious organisations. They operated to address the effects of poverty, disease, 
neglect, abandonment and being orphaned. These foundling homes and infant asylums did not have an educational focus, as they tended only to the child's health and welfare. They were staffed by nurses and nursing assistants and directed by a male, medical doctor (Gahan 2007). After World War II, the roles of many women were impacted in two ways; from being the main income earner to being unemployed, as men were given preference for employment, or becoming head of the household if widowed. It was the latter who then needed support with the care of their young children so that they could stay in or enter the workforce (Ailwood 2007). Thus, the first day care centres emerged in many areas throughout Australia in the 1950s and 1960s.

Later, in the 1970s, through the influence of other males, such as Spock, Piaget, Bandura (see Berk 2012), the educative benefits of programs for very young children was proclaimed. Therein, a schism emerged between programs that focused on the health and welfare (that is, care) of the child and those that focused on the education of the child. Middle-class women dominated early childhood education services and working-class women dominated early childhood care services, both as consumers and reproducers. In the former, middle-class women as consumers could afford the fees and the operating hours suited their stay-at-home lifestyle. They could also join their child in educational activities. As reproducers (that is, teachers), middle-class women held qualifications from middle-class institutions, such as a kindergarten teachers' college. These colleges were pseudo 'finishing schools' where teaching young children was regarded as a worthy role to undertake until the women married, when they would resign this role and become a consumer.

For working-class women, a different type of early childhood service was actualised. It focused on caring for the children whilst their mother worked. Somewhat predictably, working-class women cared for the children of other working-class women. These services operated for longer hours and during the school holidays. Staff did not need to be qualified and, thus, their wages were low and their conditions were substandard in comparison to their early childhood education 'sisters'.

My first paid employment was as a teaching assistant in a day-care center (sic). I worked with the 3-5 year old group of some 25 children with a series of co-assistants and volunteers (to keep the costs low). I worked an 8 hour day with 1 hour for lunch and 10 minutes for two tea breaks. Leave entitlements were set at 4 weeks recreational leave and 8 days sick per annum. In the early 1980s, because I held a qualification, I was paid \$4.44 per hour. When I left, after 18 months, for a job as a Teacher Assistant in a kindergarten, my hourly pay increased to $\$ 6.95$. I worked a 7 hour day and I was paid for school holidays (6 weeks) in addition to having 4 weeks annual leave. (personal comment, Childcare worker, 2011)

When this is examined further in terms of race, particularly for Indigenous Australians, the dominance of middle-class, white women serves to exacerbate the inequities through silencing our voices and constructing representations about us. Using a tenet of Critical Race Theory to critique the "norms, standards and assumptions" (Lazos Vargas 2003, 1) in early childhood education scholarship, a search of Australia's two leading early childhood education journals was undertaken. The search terms 'Aboriginal' and 'Indigenous' were used to identify papers published during the ten year time frame from 2005 to 2015. Only papers wherein the sole or main topic pertained to Indigenous Australians were selected. These papers were analysed to identify the author/s and to categorise the topics (see Table 1). 
The first journal is the Contemporary Issues in Early Childhood (CIEC) which, according to its editors, "incorporates interdisciplinary, cutting edge work" (Yelland \& Grieshaber, n.d.). The second journal is the Australasian Journal of Early Childhood (AJEC; formerly the Australian Journal of Early Childhood) published by the nation's main early childhood professional body, Early Childhood Australia. The Early Childhood Australia website claims that the AJEC is "Australia's foremost scholarly journal and the world's longestrunning major journal within the early childhood field" (Early Childhood Australia 2016).

Table 1 shows that, in the ten year period 2005 to 2015, the CIEC published four papers, but, by comparison, the AJEC published 23. Both journals published papers in categories such as early childhood services (operations), curriculum (literacy, numeracy, embedding Indigenous perspectives, Indigenous knowledge), children's readiness (for preschool and school) and disadvantage (health, access, equity, inclusion). However, only the CIEC has published papers wherein Indigenous Australians are the sole authors. In the AJEC, Indigenous Australian authors had co-authored a paper with one or more non-Indigenous authors. Over ten years, the AJEC has not published papers with Indigenous Australians as sole authors.

Table 1: Papers published about Indigenous Australian early childhood education by CIEC and AJEC

\begin{tabular}{|c|c|c|c|c|c|}
\hline \multicolumn{3}{|l|}{ CIEC } & \multicolumn{3}{|l|}{ AJEC } \\
\hline Yr: No & $\begin{array}{l}* \mid \mathrm{A} \\
\text { Author }\end{array}$ & Topic & Yr: No & $\begin{array}{l}\text { *IA } \\
\text { Author }\end{array}$ & Topic \\
\hline 2015: 0 & & & 2015: 1 & & Preschool readiness \\
\hline 2014: 0 & & & 2014: 2 & $\begin{array}{l}1(\# 3 / 4) \\
1(\# 2 / 2)\end{array}$ & $\begin{array}{l}\text { Embedding perspectives / curriculum } \\
\text { Technology / curriculum }\end{array}$ \\
\hline 2013: 2 & $\begin{array}{l}1 \text { (sole) } \\
1 \text { (sole) }\end{array}$ & $\begin{array}{l}\text { Interrogating social justice } \\
\text { Indigenous knowledges }\end{array}$ & 2013: 1 & & Operations / EC services \\
\hline 2012: 0 & & & 2012: 4 & & $\begin{array}{l}\text { Inclusion / EC services } \\
\text { Literacy / curriculum } \\
\text { Access / equity } \\
\text { Health }\end{array}$ \\
\hline 2011: 0 & & & 2011: 3 & & $\begin{array}{l}\text { Access / equity } \\
\text { School readiness } \\
\text { Literacy / curriculum }\end{array}$ \\
\hline 2010: 0 & & & 2010: 3 & $1(\# 1 / 4)$ & $\begin{array}{l}\text { Inclusion / EC services } \\
\text { Embedding perspectives / curriculum } \\
\text { Inclusion / EC services }\end{array}$ \\
\hline 2009: 0 & & & 2009: 3 & & $\begin{array}{l}\text { Inter-cultural services } \\
\text { Workforce } \\
\text { Quality / EC services }\end{array}$ \\
\hline 2008: 0 & & & 2008: 3 & $1(\# 3 / 5)$ & $\begin{array}{l}\text { Numeracy / curriculum } \\
\text { Literacy / curriculum } \\
\text { EC services / programs }\end{array}$ \\
\hline 2007: 2 & & $\begin{array}{l}\text { Research: remote IA regions } \\
\text { EC services / remote regions }\end{array}$ & 2007: 2 & $1(\# 3 / 4)$ & $\begin{array}{l}\text { Attendance } \\
\text { Workforce / teacher qualifications }\end{array}$ \\
\hline 2006: 0 & & & 2006: 0 & & \\
\hline 2005: 0 & & & 2005: 0 & & \\
\hline Total: 4 & & & Total: 23 & & \\
\hline
\end{tabular}

*IA = Indigenous Australian. \# signifies the order of IA author/total number of authors. EC = early childhood. 
The main findings uncovered in this very simple exercise highlight the racialised nature of early childhood education in Australia whereby:

- Indigenous Australians are more often the subjects of early childhood education papers;

- non-Indigenous Australians dominate the scholarship regarding Indigenous Australian early childhood education, therefore, 'talking about' Indigenous Australians has been normalised;

- topics are more likely to be about curriculum than educational inequities for Indigenous Australians-this assumes that the curriculum is neutral, not racialised;

- $\quad$ papers examining the role of Indigenous Australians as educators is limited-the subjugation has been internalised by both Indigenous and non-Indigenous Australians;

- the raced nature of early childhood education goes unstated and so remains unexamined.

Given the above, it is highly unlikely that this paper would make it through the review procedures, let alone be published in either journal. However, and as per the Introduction, the role of the NIRAKN has been instrumental in supporting the author and in advancing the scholarship of Indigenous Australian early childhood education. This is discussed in the next section.

Are there any Indigenous Australian women here? Sort of, but they're subjugated, silenced or subjectified: Examining the roles of Indigenous Australian women in early childhood education

Whilst the emergence of early childhood education in Australia is a relatively recent phenomenon, it certainly precedes that of early childhood education for young Indigenous Australian children. The systematic provision of early childhood education services (that is, kindergarten and preschool) emerged largely because of the Commonwealth Government of Australia's 1967 Referendum that enabled it to legislate and so make policy and deliver programs for Indigenous Australians.

Thus, the staffing pattern in the earliest Indigenous early childhood education programs in the 1970s was a qualified, white, female teacher and an unqualified, Indigenous Australian woman as the teacher's aide (Martin 2016; McConnochie \& Russell 1982; Teasdale \& Whitelaw 1981). Whilst data has not been consistently recorded about the workforce in these Indigenous early childhood education services, it is possible to discern the main staffing patterns. This critique is important for understanding how the scholarship has been advanced even if, as shown in Table 1, it has been established that there is a paucity of literature and research. The purpose here is to provide an overview of the roles of early childhood educators and critique how "racism is rooted in ... institutions ... culture and concepts of self-identity and group-identity" (Lazos Vargas 2003, 2).

\section{Constructions of Indigenous Australian women in early childhood education: Roles, relationships and identities}

A critique of the roles of Indigenous Australian women in early childhood education provides insights to the relationship with non-Indigenous Australian early childhood education and, therein, early childhood education overall. From the outset, this is a product of power and dominance replicated from that of the wider Australian society and its 
structures, including education. This critique is informed by a range of primary and secondary sources, wherein five constructions of Indigenous Australian women in early childhood education have been named. Each is opened with a short story to both illustrate and elucidate the roles, relationships and implications for Indigenous Australian and nonIndigenous early childhood educators. It covers the period from the 1970s to the present, but timeframes are not fixed and, whilst the constructions evolve, aspects are retained in others.

\section{Maids and Missus}

A non-Indigenous early childhood educator constantly referred to the Indigenous Australian women she worked with, many who are the same age or older than she, as 'my girls'. She shows great pride in their achievements, such as turning up to work every day and not going home early, and not faking illness to avoid attending professional development workshops. The kindergarten is recognised for its success in children's attendance and community involvement, and staff receive invitations to present this at conferences. However, not one of her 'girls' has attended these conferences with her, nor been a co-presenter of these successes.

In its infancy (pun intended) the role of an Indigenous Australian woman was to serve as an aide to the non-Indigenous Australian teacher. This involved being a 'maid' and undertaking domestic tasks to set up (for example, mixing paint, putting out chairs and tables, setting up the outside play area and the equipment as directed) and clean up (for example, sweeping floors, wiping tables, washing cups). The power was totally vested with the non-Indigenous teacher who is the qualified superior-the 'missus'. They both see no requirement for Indigenous Australian teacher aides to have qualifications. Therefore, the aide's work is devalued and not regarded as professional. This exemplifies the class division of 'missus and maid' that began in the early phases of colonisation and continued, in some regions, to the mid-1970s (Huggins 1998; Moreton-Robinson 2000).

\section{Resourceful Native and Cultural Studies Manager}

Some visitors to an Indigenous Australian early childhood education service in a remote area commented on the resources that portrayed Indigenous Australians. This included the Aboriginal flag that was pinned to a wall upside-down, the three black dolls in 'home corner' (whereas the pink dolls were being pushed in prams outside), a didgeridoo that was standing in a corner of the room with cobwebs on the mouth-piece and a poster depicting Aboriginal hunting implements. The nonIndigenous teacher explained that some of the children were 'hunting for bush-tucker' in the outside play area so she did not want to interrupt them, but, every now and then, she called out to a child in the local language. It was not until lunch time that the Indigenous Australian teacher's aide was introduced to the visitors, with an emphasis on how she was great at teaching her language, making damper, chasing away the lizards and turning natural resources into play items for the children. When the teacher was asked about the curriculum, she referred to how much it cost her to buy the cultural items.

In this construction, the role of the Indigenous Australian teacher's aide is to be both resourceful and a resource regarding Indigenous Australian culture in the early childhood education service. This relationship entails both class and race as the nonIndigenous teacher abrogates her role to teach, instead being a manager of a cultural 
studies program. The service represents itself as a museum, where objects are viewed, rather than a place where specific teaching and learning occurs. The Indigenous Australian teacher's aide, as a 'resourceful native', becomes an accomplice in realising the mediocre goals of the non-Indigenous teacher. Education inequity is compounded when essentialised constructions of Indigenous Australian cultures are used by the early childhood educators to defend their program decisions.

3. 'Projects' and Project Managers

In early 2015, I was told by a young Indigenous Australian university student that she wanted my job. She then asked what she needed to do to get it. My response was, "Get a PhD, publish, develop your scholarship, develop your networks and know how to handle the racism in all its forms".

As changes occur again in the wider structural domain of government-legislation and education-programs are established in higher education institutions to graduate Indigenous Australian teachers. Some academic staff took up roles of mentoring Indigenous Australian undergraduate teachers. Thus, the relationship between Indigenous Australian women and non-Indigenous Australian women were no longer the province of early childhood education services. The former were taken under the wings of the latter and managed as 'projects'. The power is always vested with the non-Indigenous Australian early childhood academic, whereby some, due to their experience in this type of project management, presumed authority in Indigenous Australian early childhood education. As evident in the story above, a consequence was that these Indigenous Australian women 'projects' were favoured and protected by non-Indigenous early childhood education academics, and came to believe that their indigeneity was the only criterion needed for senior roles.

4. Angels and Anglers

The author attended a conference where one of the presentations was about research undertaken in an early childhood centre in an Indigenous Australian community known to her. The presenter, a non-Indigenous woman, showed photos of an aspect about the wider Indigenous community that portrayed them negatively. Later, when this was raised with the non-Indigenous woman, she stated, more so than asked, "What's the harm?"

A critical mass of Indigenous Australians in the early childhood education workforce exists though an increase in numbers of qualified Indigenous Australian early childhood teachers and stability in employment for Indigenous Australian teacher assistants. However, the sector remains dominated by non-Indigenous women who speak of the role of cultural awareness for themselves and cultural safety for their Indigenous Australian counterparts. However, the entrenched racism that is individual and collective, structural and social, holds a twist whereby, to achieve their cultural awareness, Indigenous Australians also must ensure that non-Indigenous Australians are also culturally safe. These are tasks of angelic proportions because non-Indigenous Australian early childhood educators angled and manoeuvred the onus of responsibility to Indigenous Australians. Some, in referring to their roles of working with young children, reject the need to do either and claim that, as the children do not 'see colour', there is no issue. Most Indigenous Australian early childhood educators are unable to speak back to that naïve, but nonetheless racist, 
positioning. However, they (myself included) are not alone as the above story has a second part (see paragraph 6 below.

5. Visible and Invisible

Two First Nations women who had been sitting nearby when the discussion had occurred moved forward and, without diminishing my role or silencing me, one asked, "How can you say that? That's a question any researcher asks at the beginning of the research, not when they're presenting on it." The other then asked, "So how do you answer that?" The non-Indigenous researcher went quiet. The second woman continued, "If you can't answer that, then you need to stop what you're doing right away."

The critical mass, therefore, is not limited to Indigenous early childhood educators in Australia as these women showed. They had seen and heard the same erroneous messages in the presentation and had the same concerns. However, it is observed that whilst non-Indigenous Australian women do listen differently to others, once they return to Australia, they revert to the comfort of their class and race, as though nothing ever happened.

\section{Leaders and Leaners}

Continuing the story from paragraph 5 above, I was sitting with an Indigenous Australian woman and a member of the very same community that was being misrepresented who said nothing during either communication. For clarity, I will give this Indigenous Australian woman a pseudonym, 'Anne'. Even though Anne had expressed anger beforehand, she chose not to confront the non-Indigenous presenter, and remained quiet. Later, Anne rang me to ask if the non-Indigenous presenter had emailed me her presentation paper for comment. I asked her to check the email again to see if this was the case. When Anne found that I had not been sent the paper, she complained that she did not know how to comment on it. I advised that she should simply tell the non-Indigenous presenter this same thing and ask why she had not emailed the paper to myself. That was three weeks ago (early November 2016). I'm yet to be emailed the paper by either woman.

Whilst many Indigenous Australian early childhood educators have successfully performed leadership roles, and this is acknowledged by non-Indigenous counterparts as per the previous story, too often the former are 'leant on' by the latter or by other Indigenous Australian early childhood educators. This leadership, whilst promoted as beneficial for other Indigenous Australians, exists more so in relation to the agendas of non-Indigenous Australian early childhood educators. Where nonIndigenous Australian women seek to address power in relation to gender (the 'glass ceiling'), Indigenous Australian women seek to address power in relation to gender, class, age and status (the glass ceiling, glass slippers, glass walls and glass floor). To maintain any traction within early childhood education, some Indigenous Australian women mask leadership by 'leaning on' non-Indigenous women or 'leaning on' Indigenous Australian women to protect a persona of being non-problematic, particularly if they were/are 'projects' (see paragraph 3 above). As discussed earlier, some Indigenous teachers and aides come to believe that their main qualification is their indigeneity and, for some, a particular form of this is reminiscent of the 'maids and missus' construction (see paragraph 1 above). 


\section{The role of the NIRAKN: Changing the discourse and advancing the scholarship in Indigenous Australian early childhood education}

As most of the literature regarding Indigenous Australian early childhood education is not written by Indigenous Australians, the discourse is maintained by non-Indigenous Australians, particularly women. Having to continuously engage with this discourse, and mindful of my role in it, has meant not speaking back and asserting agency is impossible. It has required particular knowledge and specific support to do so, hence the role of the NIRAKN has been vital. It has enabled me to significantly advance the scholarship in this sector of education through its research grants program. In 2014, an application was funded to bring a number of Indigenous Australian women together in Brisbane to meet, to orient their thinking about their contributions and to understand the main aspects involved in writing and publishing. The underlying purpose was to not merely for building their capacity to write and have a voice, but for taking responsibility for this authorship and working beyond notions of colourising early childhood education in Australia.

The result has been 'Voices and Visions: Aboriginal early childhood education in Australia' (Martin 2016) a book that was reviewed by a member of the NIRAKN's Indigenous Sociology, Indigenous Knowledges \& Technology node. It is an edited collection of 'parts' and meets the criteria as a research output, thus building my capacity as an editor and writer in this field. It is published by Australia's leading publisher of early childhood education books and texts, Pademelon Press, and comprised of five parts. The first two parts purposefully discuss how and where Indigenous Australian knowledges are centred in the book and not just in Parts 3 to 5, where the stories of early childhood educators are found. For example, the following is an explanation about the distinctions between stories and yarning based on Aboriginal epistemological structures.

A story is told but a yarn is shared ... yarning is a method that purposefully brings together a number of topics in a number of layers (or threads) for a particular purpose. A yarn, therefore, is not always completed in one setting. That can leave you feeling cheated, or confused, because it does not take you to a neat conclusion nor one that is logical. A yarn has layers and a good yarn works with - in (sic) and across these layers. Yarns can be entertaining but only in equal proportion to being educational. Yarns are not instructional but they are informative. (Martin 2016, 48-49)

This book is the first of its kind, wherein Indigenous Australian early childhood educators from Queensland, New South Wales, Victoria and Western Australia give voice to and write their own stories. This serves to increase the amount of this literature and to disrupt the silences, challenge the discourses and change the constructions made by nonIndigenous early childhood educators.

As I was raised outside of the Aboriginal community, my insights into that community were based on an ignorance built on the concepts of assimilation and silence informed by my own 'mainstream' education. Over time the pedagogical absences and abuses of my own education were slowly and often painfully brought into relief. Although I had been aware almost intuitively that the framework of my education was incomplete and distorted I held no informed Aboriginal perspective through which to view this.

This perspective was predominantly provided for me by the Aboriginal Elders, including Yorta Yorta Elders involved with the Aboriginal child care course as teachers and advisors. Using the Aboriginal pedagogy of the oral tradition these Elders['] stories of mission life and political activism educated me in the genealogy of a community and the history of a culture that had survived in spite of a devastating dispossession and enormous dislocation. 
Today I have a strong sense of myself as an Aboriginal woman 30 years away from my tentative journey into engaging with my own community which began with a cautious acknowledgement of my origins. Now as an older member of the Victorian Aboriginal community, it is my turn to pass on the knowledge I have accumulated since those early steps back into a community that both tested and taught me what it means to be an Aboriginal Victorian. (Atkinson-Lopez 2016, 58)

\section{Raising the bar: The role of the NIRAKN and Aboriginal knowledges in higher education}

In this section, the role of the NIRAKN is explored in relation to raising the bar regarding Aboriginal knowledges in higher education (AKinHE). This is discussed in terms of two major research activities: An Office for Learning and Teaching fellowship (OLT, Australian Government) and an edited book of data from the 'Longitudinal Study of Indigenous Children' (Walter, Martin \& Bodkin-Andrews, 2017). Both involve support and collaboration among members of the Indigenous Sociology, Indigenous Knowledge and Technology node and the NIRAKN Management Committee.

1. Aboriginal knowledges in higher education: An Office for Learning and Teaching fellowship

When invited by senior Griffith University staff to apply for an OLT fellowship, it was a relatively straight-forward decision for the topic to investigate the role of AKinHE. This area had been identified by the Indigenous Higher Education Council (2006, 2011, 2012) and the 'Review of Higher Education Access and Outcomes for Aboriginal and Torres Strait Islander Peoples' (Behrendt et al. 2012). Therefore, it was seen as an opportunity to raise the bar in this area, not lower or maintain its current setting. From the outset, the role of the NIRAKN was instrumental, particularly when a NIRAKN Management Committee member agreed to be a referee for the application, be involved in the fellowship activities and evaluate the fellowship.

The aims of the AKinHE fellowship were to understand:

- what is known about Aboriginal* knowledges in higher education in what is now, the second decade of the twenty-first century;

- $\quad$ the roles of Aboriginal* knowledges in higher education institutions and how this contributes to the higher education experience, retention and outcomes for Indigenous Australian students and staff, and in a university's curriculum.

*as the fellowship leader is an Aboriginal woman, this work can only, at this stage, focus on Aboriginal knowledges. This is not to be taken as being exclusive of Torres Strait Islander knowledges.

It was conducted part-time over nine months (October 2014 to June 2015) and employed a hub-and-spoke model comprised of:

- Australian clusters (James Cook University; Charles Darwin University; University of Notre Dame, Australia and Griffith University);

- $\quad$ international clusters (Simon Fraser University, Vancouver and Te Wananga O Aotearoa, New Zealand); 
- a reference group (comprised of two Aboriginal community members, two Griffith University senior staff and one academic external to Griffith University);

- $\quad$ an external fellowship evaluator (Central Queensland University).

One major achievement in raising the bar, has been the development of an Aboriginal Knowledges Framework (AKF) based on Aboriginal ontology and epistemology. The AKF is employed to guide decisions regarding the policies and practices of higher education institutions. It contains a working definition of the term 'Aboriginal knowledges' and how it informs:

- $\quad$ Guiding Principles: Aboriginal students;

- $\quad$ Guiding Principles: Aboriginal staff;

- $\quad$ Guiding Principles: Curricularising Aboriginal Knowledges;

- $\quad$ Practice Guidelines and Exemplars: Curricularising Aboriginal Knowledges.

The AKinHE fellowship concluded with a national symposium in Brisbane (June 2015) attended by a number of NIRAKN members. The influences of this fellowship are ongoing as they serve to disrupt discourses within higher education institutions that diminish the role of Aboriginal knowledges. Thus, the bar was indeed raised through the identification and use of some tenets of Aboriginal ontology and epistemology in its AKF.

2. 'Growing Up Strong': An edited book regarding data from the LSIC

In addition to the above, this book also confirms how the bar has been raised through the role of the NIRAKN in producing a substantial research output and achieving its aim for collaboration and networking. With three Indigenous Sociology, Indigenous Knowledge and Technology node members (Walter, Martin \& Bodkin-Andrews) as editors and its chapters written by members of this same and other nodes, the bar was raised in the following ways. Firstly, each chapter has a sole or lead author who is Indigenous Australian. Secondly, the chapters are based on analysis of qualitative and/or quantitative data from the LSIC (Australian Government Department of Social Services). Thirdly, the chapters discuss the LSIC (its ethics and design) and cover a wide range of topics pertaining to families, identity and culture, pregnancy and birthing, employment, education, school bullying, general health and social and emotional wellbeing, and resilience and policy implications. Fourthly, it raises the level of importance of the LSIC and how Indigenous knowledges have informed it since its inception in 2003 to the present. This book, published in May, 2017, is the first of its type for Australia and so has set the bar high regarding Indigenous knowledges in research.

Not only has the book effectively built or extended the capacity of its contributors as researchers, it has been a history-making experience because it is the first and it has set the bar high. Instrumental to this is the role of the NIRAKN, its research grants program and its nodes in bringing together the researchers to progress the writing of their chapters and of the editors in completing tasks for that role.

\section{Vison fed and Vision led: What does it all mean?}

It is testimony to the vision of the NIRAKN that the works discussed above have been made possible. High praise is extended to its structure and programs in advancing the 
scholarship in Indigenous early childhood education and raising the bar regarding Indigenous knowledges in higher education. Along the way, the capacity of those involved, particularly the author of this paper, has increased and extended. Therefore, its visions have both led and fed these remarkable outcomes.

However, upon further consideration, there are some aspects where the NIRAKN vision has only been partially realised and the ground gained has been merely held. This is not a judgement of the NIRAKN, its structure or operations, as it conveys more a lack of the same visions in some early career researchers (ECRs) and post-graduate students (PGSs).

The following story is shared by me to illustrate the sequences that reveal how our work, as Indigenous Australian scholars, is never complete-that holding the ground that has been gained is sometimes all that is needed as a means to achieve what is an intergenerational vision.

At the NIRAKN Workshop in 2015, an ECR was observed rolling her eyes to two friends, both PGSs, as senior Indigenous Australian researchers shared their insights into the dangers of research and working in the academy. There was some masked giggling and rolling of eyes amongst each other. None were aware that these antics were being observed until it was pointed out to them. They did not return to the afternoon sessions for that day and avoided sitting at the same table with me.

However, the ECR was observed talking with two non-Indigenous Australian researchers who were providing their insights about working in higher education. This served to refute the comments of the senior Indigenous researchers and, more particularly, claimed it was not so racist. Months later, the ECR was known to have been employed in a fixed-term role by one of the non-Indigenous researchers. When the ECR's contract was not extended, the level of bewilderment was clearly evident in communications with more experienced Indigenous Australian researchers and academics.

Sometime later, one PGS emailed me to point out that I had incorrectly represented the name of my nation. The PGS informed me that it should be 'Quandomooka' (not Quandamoopah) because they had learned this from attending a NIRAKN Indigenous methodologies workshop. The PGS is not from my nation and, prior to the NIRAKN workshop, was unknown to me.

The second PGS was observed positioning herself with one of the senior Indigenous researchers that she had previously disrespected. When plans were being made about dinner that night, she again rolled her eyes to a different colleague as another Indigenous researcher offered suggestions. When I asked why she did that in front of the other Indigenous Australians, there was no answer, just an awkward silence. The PGS was to have been employed by the senior Indigenous researcher, but this did not eventuate.

This story demonstrates the level of subjugation by the ECR and the two PGSs who had come to believe that their indigeneity was the only qualification required in the Indigenous research and Indigenous higher education sectors. Their perceptions point not to a lack of capacity, but a lack of respect and values for those who had made ground for them to enter. Instead of contributing, they were consuming and set out to hold their tenuous ground through oppressed attitudes and oppressed behaviours. Inevitably, the story relates to the ferocity that exists within Indigenous Australian research and Indigenous Australian higher education. Whether it was the role of the NIRAKN to name and address 
this is superfluous to this paper and its discussion because it seeks to raise this as an area where the vision led by it, for some, particularly within the next generation, has not been vision fed. Now that the NIRAKN exists in a very different form, how these visions will be realised cannot be constructed as holding onto the ground that has already been gained. Much has been achieved because of a cohesive and powerful vision, not because of an absence of power and of vision. 


\section{References}

Ailwood, Jo. 2007. "Motherhood, maternalism and early childhood education: some historical connections." In Early childhood in Australia: historical and comparative contexts, edited by Jo Ailwood, 2-17. French's Forest, NSW: Pearson.

Atkinson-Lopez, Sue. 2016. "Leadership". In Voices and visions: Aboriginal early childhood education in Australia, edited by Karen L. Martin, 57-60. Mt Victoria, NSW: Pademelon Press.

Behrendt, Larissa, Steven Larkin, Robert Griew and Patricia Kelly. 2012. Review of higher education access and outcomes for Aboriginal and Torres Strait Islander people: Final report. Accessed 14 September, 2014. http://www.innovation.gov.au/lHER

Berk, Laura. 2012. Infants and children: prenatal through middle childhood. $7^{\text {th }}$ ed. Boston: Pearson, Allyn \& Bacon.

Early Childhood Australia. 2016. Australasian Journal of Early Childhood. Accessed 12 August, 2016. $\quad$ http://www.earlychildhoodaustralia.org.au/our-publications/australasian-journal-earlychildhood/

Gahan, Debbie. 2007. "Historical perspectives on kindergarten education in Queensland". In Early childhood in Australia: historical and comparative contexts, edited by Jo Ailwood, 2-17. French's Forest, NSW: Pearson.

Huggins, Jackie. 1998. Sister girl. St Lucia, Brisbane: University of Queensland Press.

Indigenous Higher Education Council. 2006. Improving Indigenous outcomes and enhancing Indigenous culture and knowledge in Australian higher education. Canberra: Australian Government Publishing Service.

Indigenous Higher Education Advisory Council. 2010. Submission to consultation paper: Meeting Australia's research workforce needs - a consultation paper to inform the development of the Australian Government's research workforce strategy. Canberra: Australian Government.

Indigenous Higher Education Council. 2011. National Indigenous higher education workforce strategy. Department of Education, Employment and Workplace Relations, Canberra: Australian Government Publishing Service.

Ladson-Billings, Gloria. 1998. "Just what is critical race theory and what's it doing in a nice field like education?" International Journal of Qualitative Studies in Education 11 (1): 7-24. Accessed 10 August, 2016. doi: 10.1080/095183998236863.

Ladson-Billings, Gloria. 2009. "Who you callin' nappy-headed? A critical race theory look at the construction of Black women". Race, Ethnicity and Education 12 (1): 87-99. Accessed 10 August, 2016. doi: 10.1080/13613320802651012.

Lazos Vargos, Sylvia. 2003. "Introduction: Critical Race Theory in education: Theory, praxis and recommendations". Counterpoints. 195:1-18. Accessed 12 August, 2016. http://www.jstor.org/stable/42978078

McConnochie, Keith and Andrew Russell. 1982. Early childhood services for Aboriginal children. Canberra: Australian Government Publishing Service.

Martin, Karen L. 2016. "Part One: Aboriginal peoples and early childhood education in Australia" In Voices and visions: Aboriginal early childhood education in Australia, edited by Karen L. Martin. 1-19. Mt Victoria, NSW: Pademelon.

Moreton-Robinson, Aileen. 2000. Talkin' up to the white women. St Lucia, Brisbane: University of Queensland Press.

Teasdale, Graham R. and Albert J. Whitelaw. 1981. The early childhood education of Aboriginal Australians. Australian Council for Educational Research: Melbourne.

Yelland, Nicola and Sue Grieshaber. n.d. Contemporary Issues in Early Childhood. Accessed 18 October, 2016. https://au.sagepub.com/en-gb/oce/node/7272/download-pdf 